\title{
Ecoacoustics: A New Science
}

Almo Farina ${ }^{1}$ and Stuart H. Gage ${ }^{2}$

${ }^{1}$ Department of Pure and Applied Sciences, Urbino University, Urbino, Italy

${ }^{2}$ Department of Entomology, Michigan State University, East Lansing, USA

\subsection{Ecoacoustics as a New Science}

Ecoacoustics is the ecological investigation and interpretation of environmental sound (Sueur and Farina 2015). It is an emerging interdisciplinary science that investigates natural and anthropogenic sounds and their relationships with the environment over multiple scales of time and space. Ecoacoustics is inclusive of the realms of ecological investigation including populations, communities, ecosystems, landscapes, and biotic regions of the Earth system. Studies of ecoacoustics in these realms can include terrestrial, freshwater, and marine systems. Ecoacoustics thus extends the scope of acoustic investigations, including bioacoustics and soundscape ecology.

Ecoacoustics studies involve the investigation of sound as a subject to understand the properties of sound, its evolution, and its function in the environment. Ecoacoustics also considers sound as an ecological attribute that can be utilized to investigate a broad array of applications including the diversity, abundance, behavior, and dynamics of animals in the environment. To facilitate this emerging new science and the investigators interested in the study of ecoacoustics, the International Society of Ecoacoustics (ISE) has recently been established and details can be found at https://sites.google.com/site/ ecoacousticssociety/. For definitions of other acoustics disciplines, see Pijanowski et al. (2011) and Farina (2014).

\subsection{Characteristics of a Sound}

Sound is a flow of energy in the form of lateral vibrations through a medium capable of oscillation. Sound is additive, meaning separate waves combine to form a single signal. The ear and brain manually separate this into distinct waves. The number of vibrations a sound produces per second is called frequency with a unit measurement of hertz. A spectrogram, commonly used to "see" a sound recording, is shown in Figure 1.1 where time is on the $\mathrm{x}$-axis (seconds), frequency is on the y-axis (kilohertz), and sound intensity (energy) is on the $\mathrm{z}$-axis. The spectrogram shown is a visual representation of a 


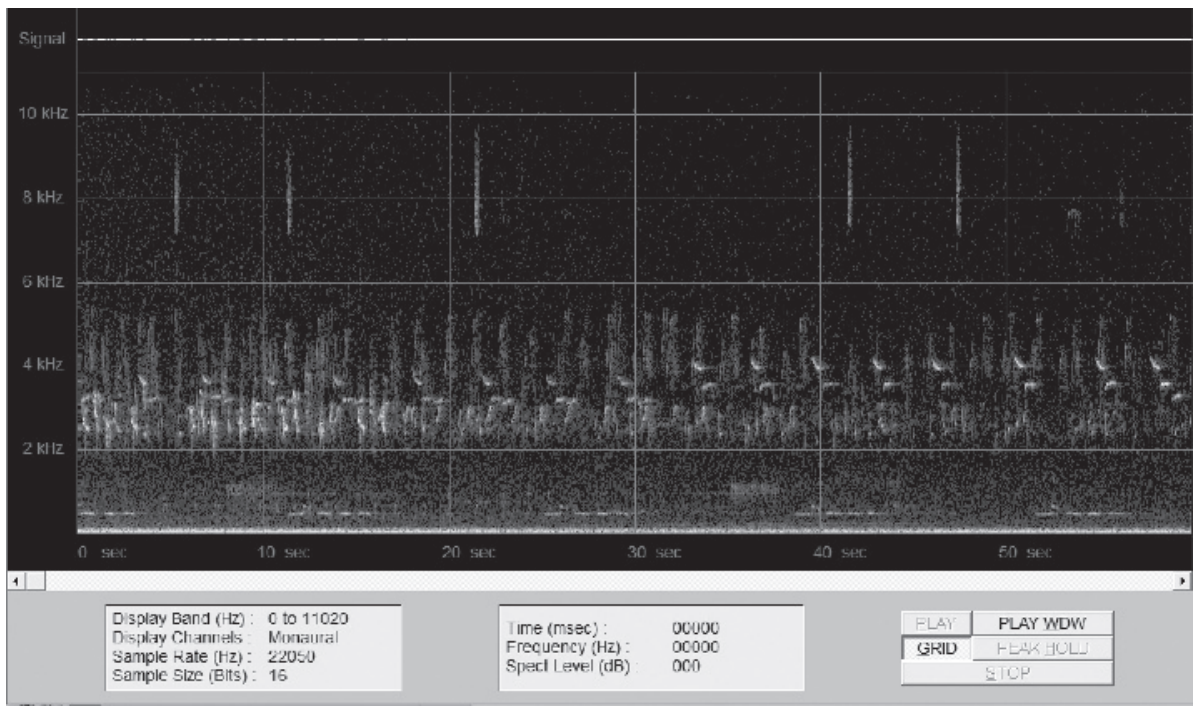

Figure 1.1 A spectrogram from a recording made at site LA00 (45.53320, -84.291960 in decimal degrees) on May 42009 at 0600h. (See color plate section for the color representation of this figure.)

sound. The creation of a sound image requires that the sound be processed using fast Fourier transform (FFT). Creating a spectrogram using the FFT is a digital process. Digitally sampled data, in the time domain, is divided into components, which usually overlap, and Fourier transformed to calculate the magnitude of the frequency spectrum for each component. Each component then corresponds to a vertical line in the image - a measurement of magnitude versus frequency for a specific moment in time. The spectra or time plots are then "laid side by side" to form the image. The sound shown in Figure 1.1 was recorded in monaural at $22050 \mathrm{~Hz}$ at site LA00 (45.53320, -84.291960 decimal degrees) on May 42009 at 0600h. Most of the sound in this recording occurs between frequencies 2 and $6 \mathrm{kHz}$ with some high-frequency sounds occurring about $8 \mathrm{kHz}$ and some low-frequency sounds at about $0.5 \mathrm{kHz}$. For those interested in the details of a mathematical treatment of acoustic signal processing, please see Hartmann (1998).

\subsection{Sound and its Importance}

Hearing is one of the five key senses (hearing, vision, touch, smell, and taste) that allow organisms in the animal kingdom to relate with the environment. Hearing is an intrinsic component of the life of many organisms, including humans. Many animals use hearing to receive signals made by the environment or by other organisms. They derive meaning from these signals, which can range from danger to courtship, and these sound signals can often mean survival or a source of food. The importance of sound to humans has diminished due to evolution, since we have built habitation and created technology that we think protects us from the outside world. As our world has become louder, due to our increasing population and technological development, we 
are becoming more sensitive to the importance of sound. Sound is the heartbeat of the biosphere, the places on Earth where life exists. If we can measure this heartbeat, we can determine the condition of the biosphere. When one scales from biosphere, to eco-region, to landscape, to ecosystem or to habitat, the sounds produced within each of these realms can determine the condition of that realm if we can determine the type of sounds being emitted.

\subsection{Ecoacoustics and Digital Sensors}

Ecoacoustics has been recognized as an approach to the study of species communication and census species over long periods of time. There have been significant changes in monitoring technology. Ecoacoustics has been developed thanks to instrumentation and analytical techniques. For instance, the microphone is an important sensor because this single instrument can serve many purposes for ecological investigations when connected to a recorder. The array of ecological attributes that can be determined by a microphone, which is an analog for hearing, is broad compared to other types of available sensors (smell, taste, vision, touch). Sensors which measure other senses are important but are not yet fully applicable to the field as is the microphone, mainly due to cost.

Studies of animal attributes by listening to their sounds can be a fruitful undertaking, especially if one enjoys listening to and documenting the occurrence of animal species during the dawn or nighttime chorus. However, there are many pitfalls, including change in species composition over season and time of day and the potential for misidentification of species. Errors in species identification are introduced because an observer cannot be at multiple places at the same time. Within the past decade, analog tape recorders have been replaced by digital recorders. Clocks have been added to recorders so that recordings can be made at specific times and other environmental sensors have been incorporated in the same recording machine. The length of a recording period was previously limited due to high power consumption by processors. Just a few years ago, it was not possible to record in a remote place without being there to manage the recording unit. Today, sound recorders can be programmed to suit a project's objective, can store many recordings on removable digital media and can remain active in the field for months without intervention. This change in technology has given rise to the use of sound as an ecological attribute. Modern acoustic sensors can be used to investigate several attributes of ecological significance. These may include practical and theoretical aspects of the environment, including acoustic identification of species in terrestrial and aquatic ecosystems; the vocal behaviors of specific organisms and their physiology; the study of noise pollution; and measuring ecological processes under a climate change scenario.

\subsection{Ecoacoustics Attributes}

A microphone and an automated recorder can provide an array of attributes that can have significant implications for theoretical and applied ecology. Important processes can be remotely investigated, including the number of species present, phenology of sound, trophic interactions, biological diversity, level of disturbance, diurnal and 
seasonal change of acoustic activity, level of habitat health, acoustic interactions between species, and complexity of the soundscape.

\subsubsection{Population Census}

Sound as a tool to survey animals has been utilized for decades (Ralph and Scott 1981). Birds are monitored by listening to the morning chorus and identifying the species based their signals at prescribed listening posts. Gage and Miller (1978) describe a longterm study using this method. Similar monitoring methods have utilized sound to determine species occurrence and abundance of amphibians using nighttime signaling (Karns 1986). The Breeding Bird Survey of North America (BBS) has been ongoing since the 1960s (Robbins and van Welzen 1967); it uses sound to determine avian species occurrence and this eco-region assessment has provided one of the longest records of bird species occurrence in North America, thus enabling the assessment of change in avian species. The surveys conducted by the BBS take place during the peak of the breeding season. The BBS routes are 24.5 miles long and there are 50 stops at every 0.5 mile along the route. Routes are randomly located in order to sample habitats that are representative of the entire region (Sauer et al. 1997). Although surveys are conducted differently in Europe, sound is used to determine the occurrence of bird species in many countries. The Pan-European Common Bird Monitoring Scheme commenced in January 2002; its main goal is to use common birds as indicators of the general state of nature using scientific data on changes in breeding bird populations across Europe (Voříšek et al. 2008).

\subsubsection{Biological Diversity}

Biological diversity is a complex ecological attribute to measure because it requires documentation of all species that inhabit a place. In addition, seasonal change can change biological diversity. Therefore, vegetation is commonly used as a surrogate for biological diversity. Measurement of the sound diversity at a site can begin to add information to the determination of biological diversity (Farina et al. 2005; Fuller et al. 2015; Sueur et al. 2008; Tucker et al. 2014).

\subsubsection{Habitat Health}

Habitat health is a relative term, but when defined by the types of sounds emitted from the site, these signals can provide an indication of the quality of that place. In fact, sounds differ in type and character depending on the types of vegetation and food available to the organisms. Benchmarks need to be established for urban, forest, grassland, and desert systems so that sounds in arrays of these systems can be compared (Fuller et al. 2015; Qi et al. 2008).

\subsubsection{Time of Arrival/Departure of Migratory Species}

The changing global climate is causing shifts in the arrival and departure times of animals that inhabit terrestrial and marine ecosystems (MacMynowski et al. 2007). Shifts in the areal pathways used by migratory animals to move from wintering sites to breeding sites may also be determined by measuring sounds along these marine or terrestrial routes. 


\subsubsection{Diurnal Change}

Daily patterns of change in animal behavior can be determined by measuring sounds emitted from a place (Farina et al. 2015). Many factors can cause diurnal change and the measurement of sound along with weather information can help to describe the magnitude of the change (Gage and Axel 2013).

\subsubsection{Seasonal Change}

Seasonal change caused by climate shifts or physical disturbance of the Earth system due to large-scale natural events or by land use change due to human development can be measured by recording sounds in a place. Seasonal change is also a natural occurrence. In temperate regions, there are shifts in animal behavior as seasons change. In spring, migratory populations of marine and terrestrial animals (mammals, fish, birds) move from overwintering habitats to breeding locations that can be far distant and require a great expenditure of energy. Food and habitat resources change and during this period, the sounds emitted from these organisms differ as they enter the breeding cycle (Gage and Axel 2013).

\subsubsection{Competition for Frequency}

The acoustic niche hypothesis (Krause 1993), an early version of the term biophony (sounds made by organisms), describes the acoustic bandwidth partitioning process that occurs in still wild biomes by which nonhuman organisms adjust their vocalizations by frequency and time-shifting to compensate for acoustic habitat occupied by other vocal creatures. Thus each species evolves to establish and maintain its own acoustic bandwidth so that its voice is not masked (Malavasi and Farina 2013). For instance, examples of clear partitioning and species discrimination can be found in the spectrograms derived from the biophonic recordings made in most uncompromised tropical and subtropical rainforests (Krause 1993).

\subsubsection{Trophic Interactions}

Many species of organisms do not emit audible sounds but those that do emit acoustic signals may depend on organisms that do not. Therefore, the presence of those that do not emit sounds may be deduced by quantifying the sounds for those that produce auditory signals. Consider birds and their food source. A wood thrush sings a beautiful song in undisturbed forests and searches and feeds on worms and other food that occurs on the forest floor. Although the food sources do not make audible sounds, the wood thrush would not occur in the habitat if it were not for the resources found there. When we hear the sound of the thrush, we can infer that there are food resources nearby and thus identify trophic interactions.

\subsubsection{Disturbance}

Disturbance can be caused by natural events (hurricanes, volcanoes, fires, floods) or by human-caused events (mining, urbanization, forest harvest, spraying). Such events are characterized by acoustic emissions. The measurement of sounds (noise) caused by disturbance can indicate the type and duration of the disturbance. The term technophony, 
the sounds made by machines, is used to characterize disturbance and can occur when an overabundance of machine sounds from aircraft, automobiles, watercraft, chain saws, etc. dominates a habitat. Usually technophony occurs at lower sound frequencies than biota so it is possible to use sound to quantify disturbance.

\subsubsection{Sounds of the Landscape and People}

Every landscape has a specific acoustic signature that is the result of the mixture of all the physical and biological acoustic agents. The measurement of the sounds emitting from a place can provide an enjoyable experience to the listener. Listening to recordings of the howl of a coyote, the yodel of a common loon or the song of a thrush can conjure up memories of a place long forgotten. Figure 1.2 provides a summary of the value of sound ranging from population census to quality assessment of the landscape for human well-being.

\subsection{Ecoacoustics and Ecosystem Management}

There are two aspects of sound that relate to ecosystem management:

- as a response indicator by estimating the diversity of vocal organisms; determining the relative proportions of human and natural activity; characterizing the daily and

\section{Ecoacoustics attributes}

Population census

Biological diversity

Habitat health

Time of arrival/departure of migratory species

Diurnal changes

Seasonal changes

Competition for frequencies

Trophic interactions

Disturbance regime

Sound of the landscape and people

Figure 1.2 Ecoacoustics has several competencies in environmental surveys, ranging from population census to quality assessment of landscape for human well-being. 
long-term trends of human and biological activity; and measuring sound in response to changes in land use.

- as a stress indicator by examining the effects of human activity on organism communication during critical functions (e.g. reproduction, food tracking, migration, etc.); determining the causes of natural population declines in organisms sensitive to human disturbance or to climate change (Krause and Farina 2016).

Sound can also be used as a management tool to regulate the amount of noise that is tolerable to humans (Farina 2014, pp. 263-296). Sound maps of urban areas, airports, manufacturing zones, and parks can be useful tools to guide the development of sound abatement regulations. Measurement of sound can be used to identify and characterize the amount of technology (trucks, cars, boats, ships, jet skis, snow machines) and the length and intensity of human-kept animals (dogs, roosters) which can be a local disturbance.

\subsection{Quantification of a Sound}

\subsubsection{Species Identification}

One can listen to the sounds in a recording and identify the entities recorded. Haselmayer and Quinn (2000) compared field observations using the point-count method of species identification by listening to recordings made at the time of the point-count and found that they are highly correlated. Joo (2009) conducted a breeding bird survey and also identified species in simultaneous recordings and found a high correlation as well. Kasten et al. (2012) provide a method to catalog species heard in a recording using a web-based tool. Automated species identification has been found to be complex due to the variability within species of songs and calls and the overlap in frequencies caused by sound emitters. Butler et al. (2007) used signatures extracted from spectrograms to search other spectrograms for that signature providing the probability of match to that signature. Match probabilities are closer to 1 for simple signatures (insects, amphibians) compared to more complex signatures (birds). However, new approaches to this problem have made major improvements in automation of species identification (Acevedo et al. 2009; Dong et al. 2015; Duan et al. 2013).

To quantify sounds recorded in the environment, the spectrogram representation can be used to create acoustics indices by dividing the spectrogram into frequency intervals and counting the pixels in each interval (Napoletano 2004). The spectrogram can also be used to select signatures of a species from the image and search a series of spectrograms for that signature (Butler et al. 2007). Since these studies were undertaken, there has been considerable improvement in the development of acoustics indices and species recognition algorithms.

\subsubsection{Acoustic Indices}

Acoustic indices are derived from environmental recordings that do not depend on the species that occur in the recordings but rather on the characteristics of the recording, including the diversity of the sounds in the recording, the complexity of the sounds, the degree of evenness of the sounds, or ratios of frequencies in the sounds. 
Seewave, a package in R developed by Sueur et al. (2008), provides functions for analyzing, manipulating, displaying, editing, and synthesizing time waves. This package processes time analysis (oscillograms and envelopes), spectral content, resonance quality factor, entropy, cross-correlation and autocorrelation, zero crossing, frequency coherence, dominant frequency, analytic signal, 2D and 3D spectrograms. Seewave enables a user to compute acoustic indices including H (Sueur et al. 2008), the Acoustic Complexity Index (ACI) (Pieretti et al.2011), and the Normalized Difference Soundscape Index (NDSI) (Kasten et al. 2012).

Soundecology, another R package focusing on acoustics, was developed by VillanuevaRivera et al. (2011) and enables a user to compute values for acoustic indices where one can specify the acoustic index and its parameters. Acoustics indices in R-Soundecology include the ACI (Pieretti et al. 2011), the Acoustic Diversity Index (Villanueva-Rivera et al.2011), the Acoustic Evenness Index (Villanueva-Rivera et al. 2011), the Bioacoustic Index (Boelman et al. 2007) and the NDSI (Kasten et al. 2012). These indices and other techniques used to interpret environmental recordings are discussed in Chapter 16. A procedure to detect and identify acoustic events, the Ecoacoustic Event Detection and Identification (EEDI) developed by Farina et al. (2016). is powered by free access software, the SoundscapeMeter 2.0 (Farina and Salutari 2016).

\subsection{Archiving Ecoacoustics Recordings}

The new types of automated recorders can be programmed to record sounds based on project objectives. Recording may be continuous or recorders may be programmed to sample the environment by having the recorder wake up, record for a length of time, then sleep until the internal clock tells the recorder to wake and record again. There are many recording options that were not possible just a few years ago. For instance, recorders can be set to record continuously for one hour before sunrise to one hour after sunrise. One can purchase such recorders from companies like Wildlife Acoustics (www.wildlifeacoustics.com), Lunilettronik (www.lunilettronik.it/) or Frontiers Lab (www.frontierlabs.com.au/) or one can construct automated recorders (Aide et al. 2013; Farina et al. 2014; Gage et al. 2015; Mason et al. 2008; Wimmer et al. 2013). These types of recorders can amass many recordings. For example, a project which has been in operation since 2009 has made over 500000 recordings to date from 12 sites at 30-minute intervals, each one minute in length (www.real.msu.edu/projects/one_proj.php?proj=la). The start and end recording dates are different depending on the intent. This requires an infrastructure to enable computation of sound metrics, storage of the sounds and their associated metrics and then retrieval of the sounds and/or the metrics for analysis. The Remote Environmental Assessment Laboratory's Digital Acoustic Library System has these features and is described in Kasten et al. (2012), while Villanueva-Rivera and Pijanowski (2012) described "Pumilio," a web-based system to archive acoustic recordings.

One may ask "Why keep all these recordings?" The answer is simple: "When the project began in 2009, automated species recognition was a dream. Now it is becoming a reality." We can then use these historical recordings to automatically identify the species in the database (Aide et al. 2013; Dong et al. 2015). To complement the issues involved in automated species identification, methods have been developed to search for specific 
frequency intervals within the digital database since vocal organisms often signal within a range of frequencies (Kasten et al. 2012).

\subsection{Ecological Forecasting}

We depend on the Earth's natural resources to sustain our economies and our life support. However, we are exploiting these resources at an unprecedented rate and thus undermining our economies and life support systems. This is a critical time in human history and we have the responsibility to measure and assess the effects of biological, chemical, physical, and human-induced change on the Earth system and its function. Ecological forecasts predict the effects of biological, chemical, physical, and humaninduced changes on ecosystems. The ecological science community is entering a new era in which forecasts of ecological change can become commonplace if we bring to bear new tools, monitoring and observing systems, and increased understanding available today and on the horizon. We are poised to capitalize on new opportunities as we significantly change the way we anticipate and manage ecological risk. Sound is one of the key ecological attributes that can be used to monitor the heartbeat of the biosphere and thus enable ecological forecasting. The advent of automated sensors is revolutionizing environmental monitoring and leading to new thrusts in environmental research and education, including ecological forecasting (NSF 2015).

\section{References}

Acevedo, MA, Corrada-Bravo, CJ, Corrada-Bravo, H, Villanueva-Riverad, LJ and Aide, TM (2009) Automated classification of bird and amphibian calls using machine learning: a comparison of methods. Ecological Informatics, 4, 206-214.

Aide, TM, Corrada-Bravo, C, Campos-Cerqueira, M, et al. (2013) Real-time bioacoustics monitoring and automated species identification. PeerJ, 1, e103.

Boelman, NT, Asner, GP, Hart, PJ and Martin, RE (2007) Multi-trophic invasion resistance in Hawaii: bioacoustics, field surveys, and airborne remote sensing. Ecological Applications, 17, 2137-2144.

Butler, RM, Servilla, Gage, S, et al. (2007) CyberInfrastructure for the analysis of ecological acoustic sensor data: a use case study in grid deployment. Cluster Comp, 10, 301.

Dong, X, Towsey, M, Truskinger, A, Cottman-Fields, M, Zhang, J and Roe, P (2015) Similaritybased birdcall retrieval from environmental audio. Ecological Informatics, 29, 66-76.

Duan, S, Zhang, J, Roe, P, et al. (2013) Timed Probabilistic Automaton: A Bridge between Raven and Song Scope for Automatic Species Recognition. Paper presented at the Twenty-Fifth IAAI Conference.

Farina, A (2014) Soundscape Ecology: Principles, Patterns, Methods and Applications, Springer Science+Business Media, Dordrecht.

Farina, A and Salutari, P (2016) Applying the Ecoacoustic Event Detection and Identification (EEDI) model to the analysis of acoustic complexity. Journal of Mediterranean Ecology, 14, 13-42.

Farina, A, Bogaert, J and Schipani, I (2005), Cognitive landscape and information: new perspectives to investigate the ecological complexity, BioSystems,79, 235-240. 
Farina, A, Pieretti, N and Piccioli L (2011), The soundscape methodology for long-term bird monitoring: A Mediterranean Europe case-study. Ecological Informatics, 6, 354-363.

Farina, A, James, P, Bobryk, C, Pieretti, N, Lattanzi, E and McWilliam, J (2014) Low cost (audio) recording (LCR) for advancing soundscape ecology towards the conservation of sonic complexity and biodiversity in natural and urban landscapes. Urban Ecosystems, 17, 923-944.

Farina, A, Ceraulo, M, Bobryk, C, Pieretti, N and Lattanzi, E (2015) Spatial and temporal variation of bird dawn choruses in a Mediterranean landscape. Bioacoustics, 24, 269-288.

Farina, A, Pieretti, N, Salutari, P, Tognari, E and Lombardi, A (2016) The application of the Acoustic Complexity Indices (ACI) to Ecoacoustic Event Detection and Identification (EEDI) modeling. Biosemiotics, 9, 227-246.

Fuller, S, Axel, AC, Tucker, D and Gage, SH (2015) Connecting soundscape to landscape: which acoustic index best describes landscape configuration?, Ecological Indicators, 58, 207-215.

Gage, SH and Axel, AC (2013) Visualization of temporal change in soundscape power of a Michigan lake habitat over a 4-year period. Ecological Informatics, 21, 100-109.

Gage, SH and Miller, CA (1978) A Long-Term Bird Census in Spruce Budworm-Prone Balsam Fir Habitats in Northwestern New Brunswick. Information Report M-X-84. Fisheries and Environment Canada, Canadian Forest Service, Maritimes Forest Research Centre, Fredericton.

Gage, SH, Joo, W, Kasten, EP, Fox, J and Biswas, S (2015) Acoustic observations in agricultural landscapes, in The Ecology of Agricultural Ecosystems: Long-Term Research on the Path to Sustainability (eds S.K. Hamilton, J.E. Doll and G.P. Robertson), Oxford University Press, New York, pp. 360-377.

Hartmann, WM (1998) Signals, Sound and Sensation (Modern Acoustics and Signal Processing), Springer, New York.

Haselmayer, J and Quinn, JS (2000) A comparison of point counts and sound recording as a bird survey method in Amazonian southeast Peru. The Condor, 102, 887-893.

Joo, W (2009) Environmental Acoustics as an Ecological Variable to Understand the Dynamics of Ecosystems, PhD dissertation, Michigan State University, East Lansing.

Karns, DR, (1986) Field Herpetology: Methods for the Study of Amphibians and Reptiles in Minnesota, Museum of Natural History, Occasional Paper 18, University of Minnesota, Minneapolis.

Kasten, E, McKinley, P and Gage, SH (2010) Ensemble extraction for classification and detection of bird species. Ecological Informatics, 5, 153-166.

Kasten, EP, Gage, SH, Fox, J and Joo, W (2012) The remote environmental assessment laboratorys acoustic library: an archive for studying soundscape ecology. Ecological Informatics, 12, 50-67.

Krause, B (1987) Bioacoustics, habitat ambience in ecological balance. Whole Earth Review, 57.

Krause, B (1993) The niche hypothesis. Soundscape Newsletter, 6, 6-10.

Krause, B and Farina, A (2016) Using ecoacoustic methods to survey the impacts of climate change on biodiversity. Biological Conservation, 195, 245-254.

MacMynowski, DP, Root, TL, Ballard, G and Geupel, G (2007) Changes in spring arrival of Neararctic-Neotropical migrants attributed to multi-scalar climate. Global Change Biology, 13, 1-13. 
Malavasi, R and Farina, A (2013) Neighbours talk: interspecific choruses among songbirds. Bioacoustics, 22(1), 33-48.

Mason, R, Roe, P,Towsey, M, Zhang, J, Gibson, J and Gage, SH (2008) Towards an Acoustic Environmental Observatory. Paper presented at the 4th IEEE International Conference on e-Science, Indianapolis, IN. DOI: 10.1109/eScience.2008.16:135-142.

Napoletano, BM (2004) Measurement, Quantification and Interpretation of Acoustic Signals within an Ecological Context. MS thesis. Michigan State University, East Lansing. NSF (2015) America's Future for Environmental Research and Education for a Thriving Century: A 10 Year Outlook. NSF Advisory Committee for Environmental Research and Education, Washington, DC.

Pieretti, N, Farina, A and Morri, D (2011) A new methodology to infer the singing activity of an avian community: the Acoustic Complexity Index (ACI). Ecological Indicators, 11, 868-873.

Pijanowski, BC, Farina, A, Gage, SH, Dumyahn, S, Krause, B (2011) What is soundscape ecology? Landscape Ecology, 2, 1213-1232.

Qi, J, Gage, SH, Joo, W, Napoletano, B and Biswas, S (2008) Soundscape characteristics of an environment: a new ecological indicator of ecosystem health, in Wetland and Water Resource Modeling and Assessment (ed. W. Ji), CRC Press, New York, pp. 201-211.

Ralph, JC and Scott, JM (1981) Estimating numbers of terrestrial birds, Studies in Avian Biology No. 6, Cooper Ornithological Society and Allen Press, Lawrence.

Robbins, CS and van Welzen, WT (1967) The Breeding Bird Survey, 1966, US Department of the Interior, Fish and Wildlife Service, Bureau of Sport Fisheries and Wildlife, Washington, DC.

Sauer, JR, Hines, JE, Gough, G, Thomas, I and Peterjohn, BG (1997) The North American Breeding Bird Survey Results and Analysis, Version 96.4, Patuxent Wildlife Research Center, Laurel.

Sueur, J and Farina, A (2015) Ecoacoustics: the ecological investigation and interpretation of environmental sound. Biosemiotics, 8, 493-502.

Sueur, J, Aubin, T and Simonis, C (2008) Seewave: a free modular tool for sound analysis and synthesis. Bioacoustics, 18, 213-226.

Sueur, J, Pavoine, S, Hamerlynck, O and Duvail, S (2008) Rapid Acoustic Survey for Biodiversity Appraisal. PLoS One, 3, e4065.

Tucker, D, Gage, SH, Williamson, I and Fuller, S (2014) Linking ecological condition and the soundscape in fragmented Australian forests. Landscape Ecology, 29, 745-758.

Villanueva-Rivera, LJ and Pijanowski, BC (2012) Pumilio: a web-based management system for ecological recordings. Bulletin of the Ecological Society of America, January.

Villanueva-Rivera, L.J, Pijanowski, BC, Doucette, J, and Pekin, B. (2011) A primer of acoustic analysis for landscape ecologists. Landscape Ecology, 26, 1233-1246.

Voříšek, P, Klvaňová, A, Wotton, S and Gregory, RD (eds) (2008) A Best Practice Guide for Wild Bird Monitoring Schemes, CSO/RSPB.

Wimmer, J, Towsey, M, Planitz, B, Williamson, I and Roe, P (2013) Analyzing environmental acoustic data through collaboration and automation. Future Generation Computer Systems, 29, 560-568. 
